\title{
Chemoenzymatic Deracemization of Secondary Alcohols Using a TEMPO-lodine-Alcohol Dehydrogenase System
}

\author{
Daniel Méndez-Sánchez, ${ }^{[a]}$ Juan Mangas-Sánchez, ${ }^{[a, b]}$ Iván Lavandera, ${ }^{[a]}$ Vicente Gotor ${ }^{[a]}$ and Vicente \\ Gotor-Fernández ${ }^{*,[a]}$
}

Abstract: A deracemization system for secondary alcohols is established after the analysis of individual steps and their compatibility in one-pot. The chemical oxidation and bioreduction occur in a sequential manner, yielding 1-arylethanols and lineal aliphatic alcohols with excellent conversions and enantiomeric excess values. The oxidation step has been performed using 2,2,6,6-tetramethyl-1-piperidinyloxyl (TEMPO) and iodine. This chemical process is extremely favoured by sonication, allowing the quantitative formation of the corresponding ketone intermediates after just one hour. A simple destruction of iodine in the same pot allows the sequential bioreduction of the ketones using either Prelog or anti-Prelog enzymes, leading to the preparation of the enantiopure alcohols with excellent yields.

Enzymes have stormed over the last decades as useful tools in the search of sustainable methodologies towards chiral compounds in theoretical $100 \%$ yield, breaking the inherent limitations associated to classical kinetic resolutions. ${ }^{[1]}$ The possibility of developing dynamic kinetic resolutions (DKRs), deracemization from racemates $^{[2]}$ or stereoselective desymmetrizations starting from prochiral or mesocompounds, ${ }^{[3]}$ allows reducing costs and the elimination of waste, which is particularly attractive for the implementation of biocatalytic strategies in the chemical industry. In this context, the most common deracemization strategies involve stereoinversion or cyclic modes.

Deracemization of a racemate by stereoinversion (Scheme 1a) consists in the selective transformation of one substrate enantiomer into a non chiral intermediate, which subsequently reacts to give the final product with opposite configuration, ideally obtaining a single enantiomer. ${ }^{[4]} \mathrm{A}$ few (chemo)enzymatic deracemization protocols have been described for the asymmetric synthesis of broad families of organic compounds such as amino acid or amino derivatives. ${ }^{[4,5]}$ Nevertheless, deracemization of secondary alcohols has attracted superior attention based on simple oxidation-reduction sequences usually accomplished by multienzymatic combos. ${ }^{[4,6]}$ With that purpose, the action and high selectivity of oxidoreductases such as alcohol dehydrogenases (ADHs) has been fully exploited. ${ }^{[7]}$ Redox enzymes are useful biocatalysts for both the oxidation of alcohols and the selective reduction of ketones using whole-cells, semi-purified or purified enzymes. ${ }^{[8]}$ In addition, it is worth mentioning that these fully enzymatic deracemizations occur under mild reaction conditions permitting the presence of additional functional groups in the reactive substrate such as esters $^{[9]}$ or carboxylic acids. ${ }^{[10]}$ a)

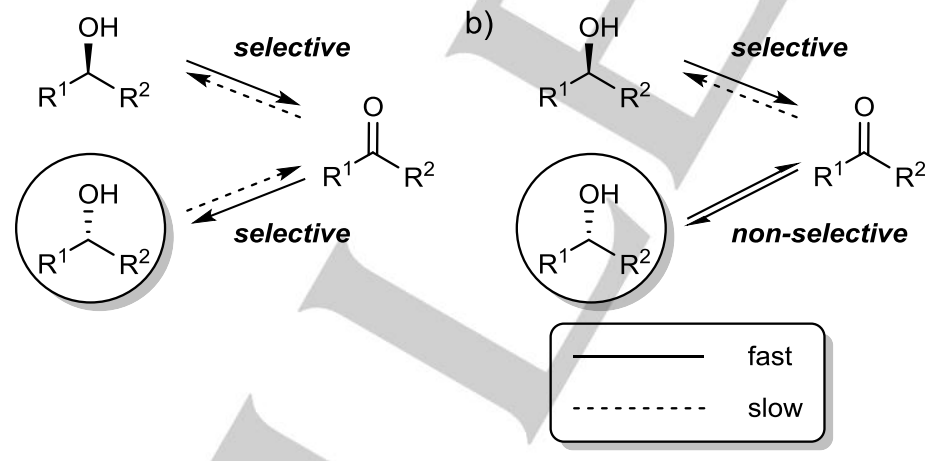

c)

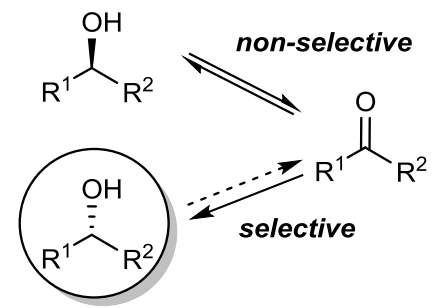

Scheme 1: Different pathways to deracemize sec-alcohols combining: a) two stereoselective steps; b) one selective step for oxidation and one non-selective step for reduction; and c) one non-selective step for oxidation and one selective step for reduction. The approach used in this article belongs to pathway $\mathrm{c}$.

[a] Mr. D. Méndez-Sánchez, Dr. J. Mangas-Sánchez, Dr. I. Lavandera, Prof. V. Gotor and Dr. V. Gotor-Fernández Organic and Inorganic Chemistry Department, Biotechnology Institute of Asturias (IUBA) University of Oviedo

Avenida Julián Clavería s/n 33006 Oviedo (Spain)

E-mail: vicgotfer@uniovi.es

[b] Dr. J. Mangas-Sánchez

Department of Biotechnology

University of Lund

PO Box 124, SE-221 00 Lund (Sweden)

Supporting information for this article is given via a link at the end of the document. 
The main difficulty of deracemization through stereoinversion resides in the perfect combination of the enantioselective oxidation and the stereoselective reduction steps without detriment in the conversion or the enantiomeric excess of the target optically active alcohol. In this sense, cyclic deracemization systems of secondary alcohols (Schemes $1 \mathrm{~b}$ and 1c) provides less exigent reaction conditions as they make use of a non-selective process. One approach can be the selective (enzymatic) oxidation of one enantiomer into the ketone, followed by a non-selective chemical reduction in a stepwise fashion (Scheme 1b). ${ }^{[11]}$ On the other hand, it is also possible to achieve a deracemization combining a non-selective oxidation step of the alcohol with a stereoselective (enzymatic) reduction of the prochiral ketone formed (Scheme 1c). This synthetic strategy has been satisfactorily reported using as oxidant a metal complex ${ }^{[12]}$ or applying other redox biocatalysts such as laccases in combination with TEMPO.$^{[13]}$ Obviously, in this case the oxidation reaction must be quantitative to obtain a proper deracemization protocol.

Herein, we report a versatile and commonly applicable deracemization strategy for secondary alcohols involving a nonselective chemical oxidation employing the iodine/TEMPO system and a stereoselective bioreduction step. After optimization of the individual processes, both will be combined in a one-pot and stepwise manner, yielding the $(R)$ - or $(S)$-alcohols depending on the stereopreference of the $A D H$ used in the reduction of the ketone intermediate.

The oxidation of alcohols for the formation of carbonyl compounds is a key reaction in organic synthesis. ${ }^{[14]}$ Therefore a number of strategies have appeared in the literature involving metal or organic oxidants such as chromium(VI) salts, manganese dioxide, activated dimethyl sulfoxides or hypervalent iodine reagents, among others. In the search for a simple compatible approach with the bioreduction process, the use of catalytic amounts of 2,2,6,6-tetramethyl-1-piperidinyloxyl (TEMPO) in combination with several oxidizing agents, were tested to oxidize the model substrate 1-phenylethanol (1a). A premise for this study was the development of the oxidative process in a buffer system, medium required for the $A D H$ catalyzed bioreduction (Scheme 2). A Tris- $\mathrm{HCl}$ buffer $\mathrm{pH} 7.5$ and a catalytic amount of TEMPO were initially selected for screening. A series of oxidants were tested such as sodium hypochlorite $(\mathrm{NaOCl}),{ }^{[15]}$ phenyliodine(III) diacetate (PIDA), ${ }^{[16]} \mathrm{N}$ chlorosuccinimide (NCS), ${ }^{[17]}$ and iodine,${ }^{[18]}$ were used in slight excess at different temperatures $\left(30-50{ }^{\circ} \mathrm{C}\right)$, finding significant conversions into acetophenone (2a).

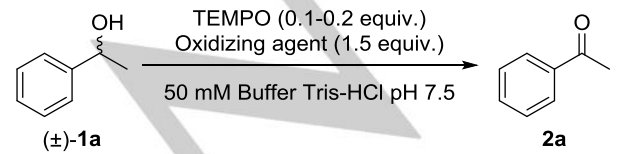

Scheme 2: Oxidation of $( \pm)$-1-phenylethanol (1a) with catalytic TEMPO and different oxidizing agents in a Tris- $\mathrm{HCl}$ buffer $\mathrm{pH} 7.5$.
Once the chemical oxidation of a series of secondary alcohols was explored, we focused in the bioreduction step of $\mathbf{2 a}$ using a Prelog $\mathrm{ADH}$ as the one from Rhodococcus ruber (ADH$A)^{[19]}$ and 2-PrOH $(6.4 \% \mathrm{v} / \mathrm{v})$ as hydrogen donor in a "coupledsubstrate" approach. ${ }^{[20]}$ To identify compatible conditions with the oxidizing systems, the bioreduction of $2 \mathbf{a}$ was studied in the presence of the previously tested chemical oxidants using favourable conditions for the overexpressed ADH-A-mediated reductions (Table 1).

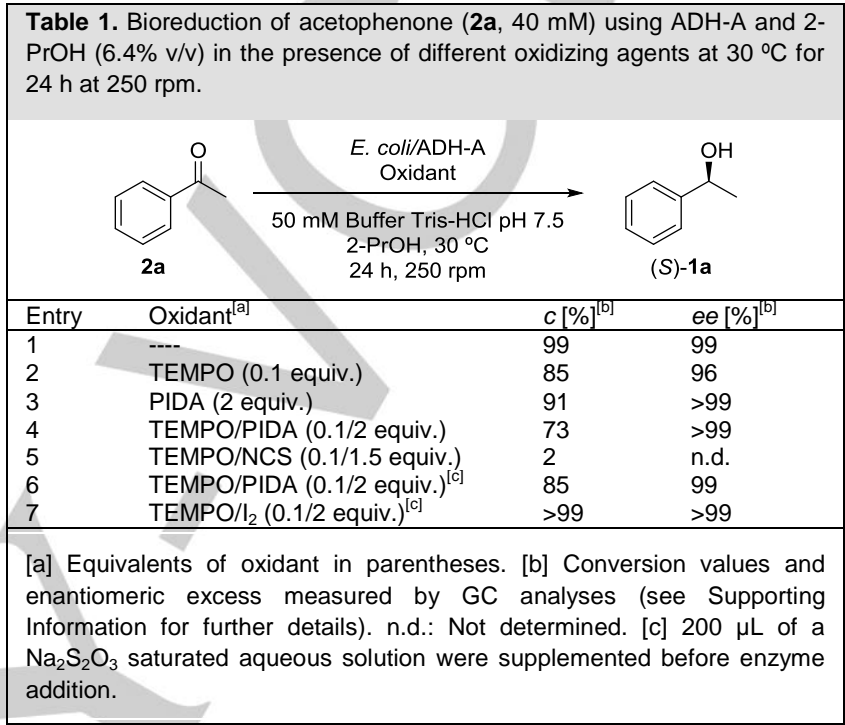

The enantiomeric excess of (S)-1-phenylethanol was slightly affected by the presence of TEMPO or PIDA observing a notably decrease in the conversion (entries 2-4), that dramatically diminished when using NCS (entry 5). In the search for compatible redox conditions for the overall deracemization process, iodine was then selected as the oxidant since it can be easily quenched afterwards by sodium thiosulfate, converting the excess of iodine in harmless iodide anions (entries 6 and 7). With this treatment, ADH-A activity remained unaltered in the stereoselective reduction of acetophenone, obtaining total conversion in the bioreduction step (entry 7 ). In summary, iodine was selected as a mild oxidant mainly for two important reasons. On the one hand, it allows the simple reoxidation of TEMPO $(0.1$ equiv.) in aqueous medium under mild reaction conditions. On the other hand, the destruction of the iodine excess to iodide ions can be accomplished in one-pot without detriment of the enzymatic activity, which is in contrast with the inhibition or competitive oxidative reverse reaction observed with other oxidants tested in this study.

Once a convenient oxidation protocol was found, an exhaustive optimization study was performed searching for suitable conditions for the complete oxidation of 1-phenylethanol (Table 2). Different parameters that could affect the reactivity of the catalytic TEMPO-iodine system were analyzed, such as the amount of TEMPO, iodine equivalents, substrate concentration, $\mathrm{pH}$ and temperature. 


\begin{tabular}{|c|c|c|c|c|c|c|c|}
\hline & & & $\underbrace{\mathrm{OH}}_{\xi}$ & $\begin{array}{l}\mathrm{O}, \mathrm{I}_{2} \\
\text { Tris } \\
{ }^{\circ} \mathrm{C}\end{array}$ & O & & \\
\hline Entry & TEMPO (eq) & $\mathrm{I}_{2}(\mathrm{eq})$ & 1a $(\mathrm{mM})$ & $\mathrm{pH}$ & $\mathrm{T}\left({ }^{\circ} \mathrm{C}\right)$ & $t(h)$ & $c[\%]^{[a]}$ \\
\hline 1 & 0.1 & 1.5 & 40 & 7.5 & 30 & 16 & 16 \\
\hline 2 & 0.2 & 1.5 & 40 & 7.5 & 30 & 16 & 23 \\
\hline 3 & 0.1 & 2 & 40 & 7.5 & 30 & 16 & 18 \\
\hline $4^{[\mathrm{b}]}$ & 0.1 & 1.5 & 40 & 7.5 & 30 & 16 & 14 \\
\hline 5 & 0.1 & 1.5 & 40 & 9 & 30 & 16 & 48 \\
\hline 6 & 0.2 & 1.5 & 40 & 9 & 30 & 16 & 54 \\
\hline 7 & 0.2 & 1.5 & 80 & 9 & 30 & 16 & 30 \\
\hline 8 & 0.2 & 1.5 & 160 & 9 & 30 & 16 & 22 \\
\hline 9 & 0.2 & 1.5 & 20 & 9 & 30 & 16 & 49 \\
\hline 10 & 0.2 & 1.5 & 40 & 9 & 60 & 16 & 52 \\
\hline 11 & 0.2 & 1.5 & 20 & 9 & 60 & 16 & 57 \\
\hline 12 & 0.2 & 1.5 & 20 & 10 & 30 & 16 & 52 \\
\hline 13 & 0.2 & 1.5 & 20 & 10 & 60 & 16 & 60 \\
\hline $14^{[\mathrm{C}]}$ & 0.2 & 1.5 & 20 & 10 & 30 & 1 & 98 \\
\hline
\end{tabular}

The first attempts for the oxidation of 1a were performed

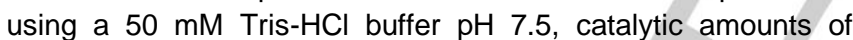
TEMPO (0.1-0.2 equiv.) and an excess of iodine (1.5-2 equiv), obtaining low conversions (entries 1-3). The presence of a hydrophobic cosolvent such as hexane $(10 \% \mathrm{v} / \mathrm{v}$, entry 4$)$ did not lead to any improvement. A significant increase in the conversion values was achieved at $\mathrm{pH} 9$ (entry 5), surpassing the $50 \%$ conversion when 0.2 equiv. of TEMPO was employed (entry 6). This is due to the fact that TEMPO works better under basic conditions. Unfortunately, the activity of the system dramatically decreased at higher substrate concentrations (80$160 \mathrm{mM}$, entries 7 and 8). Similar results were attained using lower alcohol concentrations or higher temperatures (entries 911). A similar trend was observed using Tris- $\mathrm{HCl}$ buffer $\mathrm{pH} 10$ (entries 12 and 13). Remarkably, the oxidation of 1a was almost complete after sonication of the reaction for $1 \mathrm{~h}$ (entry 14).

Once the optimal conditions were found for the oxidation of 1a, the extension of this methodology to a series of aromatic and aliphatic racemic alcohols was considered (Table 3). Different pattern substitutions were chosen in the meta-position of the aromatic ring (methoxy, chlorine and nitro, entries 2-4), studying also the effect of the same substituent at different positions of the phenyl moiety (chlorine, entries 4-6). In addition, $\beta$ chlorinated (entry 7) and aliphatic (entries 8 and 9) alcohols were finally selected to have a broader overview about the potential of this oxidizing system.

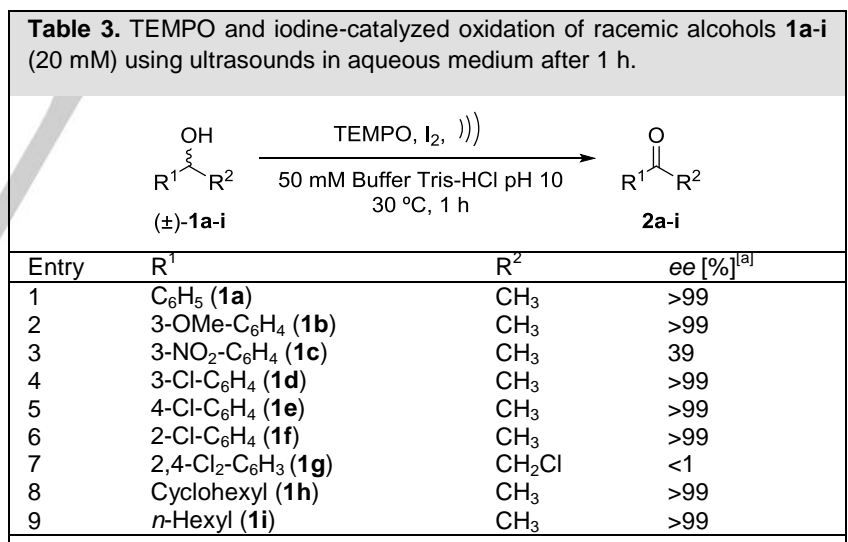

[a] Conversion values measured by GC analyses (see Supporting Information for further details). ))) stands for sonication.

Focusing on meta-substituted substrates, complete conversions were found with a moderate activating (entry 2) or deactivating group (entry 4). On the contrary, a strong electronwithdrawing group such as the nitro functionality, led to a poor $39 \%$ conversion when using this oxidizing system (entry 3 ). Regardless of the position of the chlorine substituent, the catalytic system was active, finding in all cases quantitative conversions (entries 4, 5 and 6). Nevertheless, the oxidation of substrate $\mathbf{1 g}$ with a chlorine atom at $\beta$-position, did not proceed at any extension (entry 7 ). This result can be explained as these 
activated alcohols can just be oxidized under strong conditions. $^{[21]}$ Finally, aliphatic alcohols reacted effectively yielding 1-cyclohexylethanone (entry 8) and 2-octanone (entry 9) in quantitative conversion.

Once that the TEMPO/iodine system was found to be efficient for the complete chemical oxidation of secondary alcohols (Table 3), E. coli/ADH-A without the need of an external cofactor, ${ }^{[19]}$ was used in a stepwise fashion to reduce the corresponding ketones based on the excellent activity of this enzyme under the conditions of the oxidative process as shown in Table 1. Gratifyingly, the corresponding (S)-alcohols were produced in enantiopure form and with conversion over $95 \%$ starting from the racemic forms (Table 4).

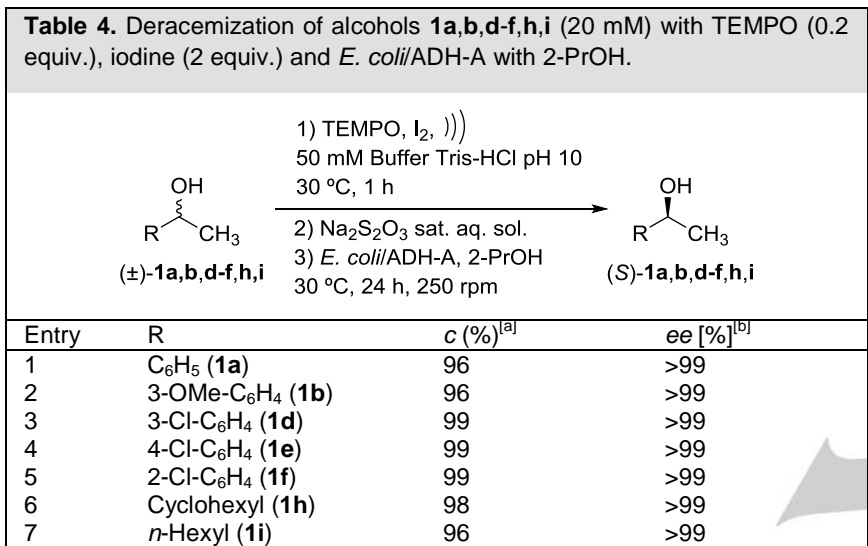

[a] Conversion values of the bioreduction reaction measured by GC analyses (see Experimental section for further details). [b] Enantiomeric excess values of the resulting deracemized alcohols measured by chiral GC analyses (see Supporting Information for further details). ()) ) stands for sonication.

Trying to obtain their alcohol antipodes, anti-Prelog ADHs were tested in the bioreduction step of the sequential deracemization (Table 5). For this study, two different semipurified enzymes were considered: the NADPH-dependent from Lactobacillus brevis (LBADH), ${ }^{[2]}$ and the NADH-dependent and commercially available evo-1.1.200. ${ }^{[23]}$ Satisfactorily all the substrates were recognized by both enzymes, so after the chemical oxidation and quenching, the stereoselective bioreduction of the corresponding ketones led to the enantiopure $(R)$-alcohols with conversions over $90 \%$.

In conclusion, chemoenzymatic deracemization strategies offer significant advantages in chemical synthesis for the preparation of enantiopure compounds with high yields. DKR have been fully exploited along the last two decades, while other deracemization strategies using redox processes combining chemical and enzymatic catalysts have been less explored. Herein, we have developed a deracemization protocol for secondary alcohols based on the chemical oxidation of the racemates and the sequential bioreduction of the intermediate ketones formed in the same vessel. A simple and cheap system such as TEMPO together with iodine has allowed the effective oxidation of the alcohols, requiring ultrasound conditions for the fast quantitative formation of the ketones after just $1 \mathrm{~h}$. This system has been fully compatible with the ADH-catalyzed bioreduction of the resulting ketones, after quenching of the iodine excess with an aqueous $\mathrm{Na}_{2} \mathrm{~S}_{2} \mathrm{O}_{3}$ saturated solution. Gratifyingly, different Prelog and anti-Prelog alcohol dehydrogenases have efficiently mediated the preparation of enantiopure $(S)$ and $(R)$-alcohols with conversions over $90 \%$, starting from the unexpensive racemates.

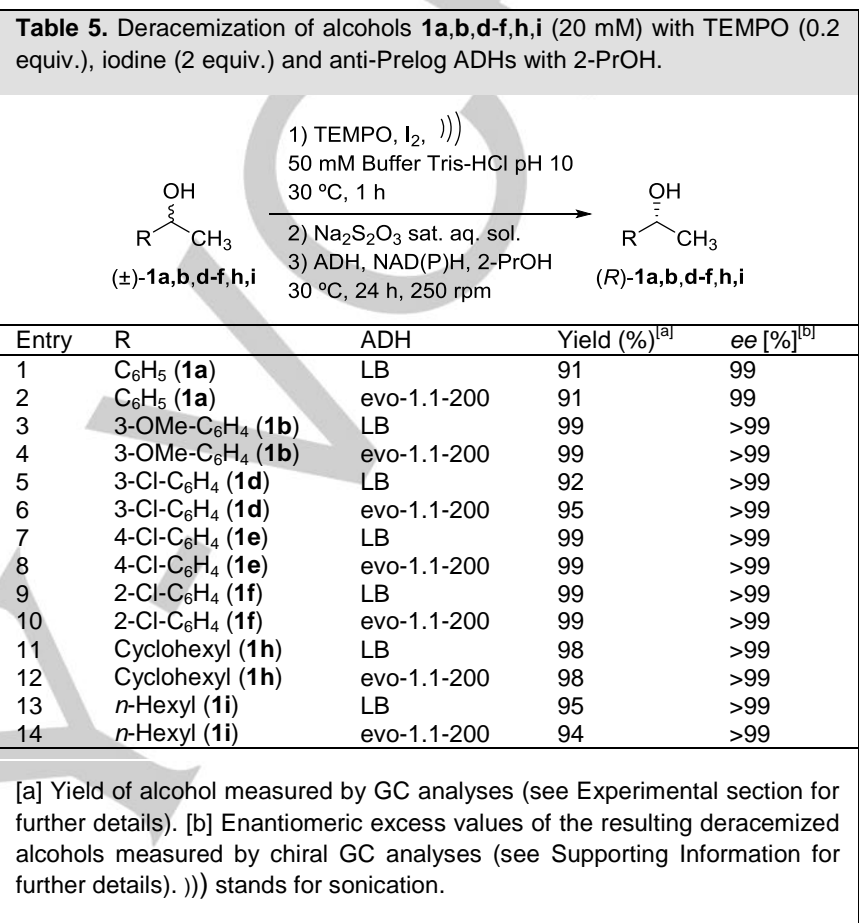

\section{Experimental Section}

Chemical reagents were purchased from different commercial sources (Sigma-Aldrich, Acros and Fluka) and used without further purification. Alcohol dehydrogenase from Lactobacillus brevis (LBADH, $300 \mathrm{U} / \mathrm{mL})$ was purchased from Codexis. Evo-1.1.200 (1716 U/mg) was acquired from Evocatal. E. coli strains to overexpress ADH-A from Rhodococcus ruber were kindly provided by Prof. Wolfgang Kroutil (University of Graz). GC analyses were carried out for conversion and enantiomeric excess measurements (see Supporting Information).

Chemical oxidations. Over a solution of the corresponding alcohol 1a-i $(0.08 \mathrm{mmol}, 20 \mathrm{mM})$ in a $50 \mathrm{mM}$ Tris- $\mathrm{HCl}$ buffer at $\mathrm{pH} 10(4 \mathrm{~mL})$, iodine (1.5 equiv., $30 \mathrm{mg}$ ) and TEMPO (0.1-0.2 equiv., $2.5-5 \mathrm{mg}$ ) were successively added in a $15-\mathrm{mL}$ falcon tube. The mixture was sonicated for $1 \mathrm{~h}$ and conversions were measured by $\mathrm{GC}$ analysis.

General procedure for the bioreduction of ketones 2a-i with ADH-A overexpressed in $\boldsymbol{E}$. coli. In an Eppendorf tube containing 2a-i (0.08 $\mathrm{mmol})$ in $50 \mathrm{mM}$ Tris-HCl buffer $\mathrm{pH} 10(468 \mu \mathrm{L})$, E. coli/ADH-A cells (15 $\mathrm{mg})$ and 2-PrOH $(32 \mu \mathrm{L})$ were successively added. The reaction was shaken at $30 \stackrel{\circ}{\circ}$ and $250 \mathrm{rpm}$ for $24 \mathrm{~h}$. Then, the mixture was extracted with EtOAc $(2 \times 500 \mu \mathrm{L})$, centrifuged (13,000 rpm, $90 \mathrm{sec})$ and dried over $\mathrm{Na}_{2} \mathrm{SO}_{4}$. The substrate conversion and the enantiomeric excess of the corresponding alcohol 1a-i were measured by GC analysis. 
General procedure for the bioreduction of ketones 2a-i with LBADH. In an Eppendorf tube containing 2a-i $(0.08 \mathrm{mmol})$ in $50 \mathrm{mM}$ Tris- $\mathrm{HCl}$ buffer $\mathrm{pH} 10(468 \mu \mathrm{L})$, LBADH cells $(10 \mu \mathrm{L}, 3 \mathrm{U}), 1 \mathrm{mM}$ NADPH $(60 \mu \mathrm{L}$ of a $10 \mathrm{mM}$ stock solution), $1 \mathrm{mM} \mathrm{MgCl}_{2}$ (60 $\mu \mathrm{L}$ of a $10 \mathrm{mM}$ stock solution) and $2-\mathrm{PrOH}(32 \mu \mathrm{L})$ were successively added. The reaction was shaken at $30{ }^{\circ} \mathrm{C}$ and $250 \mathrm{rpm}$ for $24 \mathrm{~h}$. Then, the mixture was extracted with EtOAc $(2 \times 500 \mu \mathrm{L})$, centrifuged $(13,000 \mathrm{rpm}, 90 \mathrm{sec})$ and dried over $\mathrm{Na}_{2} \mathrm{SO}_{4}$. The substrate conversion and the enantiomeric excess of the corresponding alcohol 1a-i were measured by GC analysis.

General procedure for the bioreduction of ketones 2a-i with evo1.1.200. In an Eppendorf tube containing 2a-i $(0.08 \mathrm{mmol})$ in $50 \mathrm{mM}$ Tris$\mathrm{HCl}$ buffer $\mathrm{pH} 10(468 \mu \mathrm{L})$, evo-1.1.200 (50 $\mu \mathrm{L}, 3 \mathrm{U}), 1 \mathrm{mM}$ NADH $(60 \mu \mathrm{L}$ of a $10 \mathrm{mM}$ stock solution), $1 \mathrm{mM} \mathrm{MgCl} 2$ (60 $\mu \mathrm{L}$ of a $10 \mathrm{mM}$ stock solution) and 2- $\mathrm{PrOH}(25 \mu \mathrm{L})$ were successively added. The reaction was shaken at $30 \stackrel{\circ}{\circ}$ and $250 \mathrm{rpm}$ for $24 \mathrm{~h}$. Then, the mixture was extracted with EtOAc $(2 \times 500 \mu \mathrm{L})$, centrifuged (13,000 rpm, $90 \mathrm{sec})$ and dried over $\mathrm{Na}_{2} \mathrm{SO}_{4}$. The substrate conversion and the enantiomeric excess of the corresponding alcohol 1a-i were measured by GC analysis.

Deracemization experiments using ADH-A overexpressed in E.coli. Over a solution of the corresponding alcohol 1a-i $(0.8 \mathrm{mmol}, 20 \mathrm{mM})$ in a $50 \mathrm{mM}$ Tris- $\mathrm{HCl}$ buffer $\mathrm{pH} 10(4 \mathrm{~mL})$, iodine (1.5 equiv., $30 \mathrm{mg}$ ) and TEMPO (0.1 equiv., $2.5 \mathrm{mg}$ ) were successively added. The mixture was sonicated for $1 \mathrm{~h}$ at room temperature until complete conversion to the corresponding ketone $\mathbf{2 a}$-i. After this time, the reaction was stopped by adding a saturated $\mathrm{Na}_{2} \mathrm{~S}_{2} \mathrm{O}_{3}$ aqueous solution $(300 \mu \mathrm{L})$. A $500 \mu \mathrm{L}$-aliquot was then withdrawn, and E. coli/ADH-A cells (15 mg) and 2-propanol (32 $\mu \mathrm{L})$ were successively added. The reaction was shaken at $30^{\circ} \mathrm{C}$ and 250 rpm for additional $24 \mathrm{~h}$. Then, the mixture was extracted with EtOAc ( $2 \mathrm{x}$ $500 \mu \mathrm{L})$, centrifuged $(13,000 \mathrm{rpm}, 90 \mathrm{sec})$ and dried over $\mathrm{Na}_{2} \mathrm{SO}_{4}$. The substrate conversion and enantiomeric excess of the corresponding $(S)$ alcohols 1a-i were measured by GC analysis.

Deracemization experiments using LBADH. Over a solution of the corresponding alcohol 1a-i $(0.8 \mathrm{mmol}, 20 \mathrm{mM})$ in $50 \mathrm{mM}$ Tris- $\mathrm{HCl}$ buffer $\mathrm{pH} 10$ (4 mL), iodine ( 1.5 equiv., $30 \mathrm{mg}$ ) and TEMPO (0.1 equiv., $2.5 \mathrm{mg}$ ) were successively added. The mixture was sonicated for $1 \mathrm{~h}$ at room temperature until complete conversion to the corresponding ketone $\mathbf{2 a - i}$. After this time, the reaction was stopped by adding a saturated $\mathrm{Na}_{2} \mathrm{~S}_{2} \mathrm{O}_{3}$ aqueous solution $(300 \mu \mathrm{L})$. A $500 \mu \mathrm{L}$ aliquot was then withdrawn, and a LBADH stock $(10 \mu \mathrm{L}, 3 \mathrm{U})$ in $50 \mathrm{mM}$ Tris-HCl buffer $\mathrm{pH} 10,1 \mathrm{mM} \mathrm{MgCl}$ ( $60 \mu \mathrm{L}$ of a $10 \mathrm{mM}$ stock solution), 2-PrOH (32 $\mu \mathrm{L}$ ) and $1 \mathrm{mM} \mathrm{NADPH} \mathrm{(60}$ $\mu \mathrm{L}$ of a $10 \mathrm{mM}$ stock solution) were successively added. The reaction was shaken at $30{ }^{\circ} \mathrm{C}$ and $250 \mathrm{rpm}$ for additional $24 \mathrm{~h}$. Then, the mixture was extracted with EtOAc $(2 \times 500 \mu \mathrm{L})$, centrifuged $(13,000 \mathrm{rpm}, 90 \mathrm{sec})$ and dried over $\mathrm{Na}_{2} \mathrm{SO}_{4}$. The substrate conversion and enantiomeric excess of the corresponding $(R)$-alcohols $1 \mathbf{a}$-i were measured by GC analysis.

Deracemization experiments using ADH evo-1.1.200. Over a solution of the corresponding alcohol 1a-i $(0.8 \mathrm{mmol}, 20 \mathrm{mM})$ in $50 \mathrm{mM}$ Tris- $\mathrm{HCl}$ buffer $\mathrm{pH} 10(4 \mathrm{~mL})$, iodine ( 1.5 equiv., $30 \mathrm{mg}$ ) and TEMPO (0.1 equiv., $2.5 \mathrm{mg}$ ) were successively added. The mixture was sonicated for $1 \mathrm{~h}$ at room temperature until complete conversion to the corresponding ketone 2a-i. After this time, the reaction was stopped by adding a saturated $\mathrm{Na}_{2} \mathrm{~S}_{2} \mathrm{O}_{3}$ aqueous solution $(300 \mu \mathrm{L})$. A $500 \mu \mathrm{L}$ aliquot was then withdrawn, and evo-1.1.200 (3 U), $10 \mathrm{mM} \mathrm{NADH}(50 \mu \mathrm{L}), 10 \mathrm{mM} \mathrm{MgCl}$ $(50 \mu \mathrm{L})$ and $2-\mathrm{PrOH}(25 \mu \mathrm{L})$ were successively added. The reaction was shaken at $30{ }^{\circ} \mathrm{C}$ and $250 \mathrm{rpm}$ for additional $24 \mathrm{~h}$. Then, the mixture was extracted with EtOAc $(2 \times 500 \mu \mathrm{L})$, centrifuged (13,000 rpm, $90 \mathrm{sec})$ and dried over $\mathrm{Na}_{2} \mathrm{SO}_{4}$. The substrate conversion and enantiomeric excess of the corresponding $(R)$-alcohols $\mathbf{1 a - i}$ were measured by $\mathrm{GC}$ analysis.

\section{Acknowledgements}

Financial support from the Spanish Ministerio de Economía y Competitividad (CTQ-2013-44153-P), the Principado de Asturias (SV-PA-13-ECOEMP-42) and the University of Oviedo (UNOV13-EMERG-01) are gratefully acknowledged.

Keywords: Alcohols • Biocatalysis • Deracemization • Oxidoreductases • TEMPO

[1] N. J. Turner, Chem. Commun. 2015, 51, 450-464.

[2] a) N. J. Turner, Curr. Opin. Chem. Biol. 2010, 14, 115-121; b) A. Díaz Rodríguez, I. Lavandera, V. Gotor, Curr. Green Chem. 2015, 2, 192211.

[3] E. García-Urdiales, I. Alfonso, V. Gotor, Chem. Rev. 2011, 111, PR110 PR180.

[4] C. C. Gruber, I. Lavandera, K. Faber, W. Kroutil, Adv. Synth. Catal. 2006, 348, 1789-1805.

[5] a) S. Servi, D. Tessaro, G. Pedrocchi-Fantoni, Coord. Chem. Rev. 2008 , 252, 715-726; b) M. Rachwalski, N. Vermue, P. J. T. Rutjes, Chem. Soc. Rev. 2013, 42, 9268-9282.

[6] C. V. Voss, C. C. Gruber, W. Kroutil, Synlett 2010, 991-999.

[7] a) C. V. Voss, C. C. Gruber, W. Kroutil, Angew. Chem., Int. Ed. 2008 47, 741-745; Angew. Chem. 2008, 120, 753-757; b) C. V. Voss, C. C. Gruber, K. Faber, T. Knaus, P. Macheroux, W. Kroutil, J. Am. Chem. Soc. 2008, 130, 13969-13972; c) S. M. Mantovani, C. F. F. Angolini, A J. Marsaioli, Tetrahedron: Asymmetry 2009, 20, 2635-2638; d) Y.-L. Li, J.-H. Xu, Y. Xu, J. Mol. Catal. B: Enzym. 2010, 64, 48-52; e) T. Saravanan, R. Selvakumar, M. Doble, A. Chadha, Tetrahedron: Asymmetry 2012, 23, 1360-1368; f) M. C. Fragnelli, P. Hoyos, D. Romano, R. Gandolfi, A. R. Alcántara, F. Molinari, Tetrahedron 2012, 68, 523-528; g) A. M. Amrutkar, L. Banoth, U. C. Banerjee, Tetrahedron Lett. 2013, 54, 3274-3277; h) T. Cazzeta, P. J. S. Moran, J. A. R. Rodrigues, J. Mol. Catal. B: Enzym. 2014, 109, 178-183; i) D. J. Palmeira, L. S. Araújo, J. C. Abreu, L. H. Andrade, J. Mol. Catal. B. Enzym. 2014, 110, 117-125; j) T. Janeczko, E. Kostrzewa-Susłow, Tetrahedron: Asymmetry 2014, 25, 1264-1269.

[8] a) T. Matsuda, R. Yamanaka, K. Nakamura, Tetrahedron: Asymmetry 2009, 20, 513-557; b) G. de Gonzalo, A. A. Orden, F. R. Bisogno, Curr Org. Chem. 2012, 16, 2598-2612.

[9] T. Saravanan, A. Chadha, Tetrahedron: Asymmetry 2010, 21, 2973 2980

[10] Y.-P. Xue, Y.-G. Zheng, Y.-Q. Zhang, J.-L. Sun, Z.-Q. Liu, Y.-C. Shen, Chem. Commun. 2013, 49, 10706-10708.

[11] C. Magallanes-Noguera, M. M. Ferrari, M. Kurina-Sanz, A. A. Orden, J. Biotechnol. 2012, 160, 189-194.

[12] a) G. R. A. Adair, M. J. Williams, Chem. Commun. 2005, 5578-5579; b) F. G. Mutti, A. Orthaber, J. H. Schrittwieser, J. G. de Vries, R. Pietschnig, W. Kroutil, Chem. Commun. 2010, 46, 8046-8048.

[13] a) K. Kędziora, A. Díaz-Rodríguez, I. Lavandera, V. Gotor-Fernández, V. Gotor, Green Chem. 2014, 16, 2448-2453; b) A. Díaz-Rodríguez, N Ríos-Lombardía, J. H. Sattler, I. Lavandera, V. Gotor-Fernández, W. Kroutil, V. Gotor, Catal. Sci. Technol. 2015, 5, 1443-1446.

[14] a) R. C. Larock, Comprehensive Organic Transformations, A Guide to Functional Group Preparations, 2nd Ed., Wiley-VCH: New York, 1999; b) C. Parmeggiani, F. Cardona, Green Chem. 2012, 14, 547-564.

[15] N. Fukuda, M. Izumi, T. Ikemoto, Tetrahedron Lett. 2015, 56, 39053908

[16] A. De Mico, R. Margarita, L. Parlanti, A. Vescovi, G. Piancatelli, J. Org Chem. 1997, 62, 6974-6977.

[17] J. Einhorn, C. Einhorn, F. Ratajczak, J.-L. Pierre, J. Org. Chem. 1996 $61,7452-7454$.

[18] R. A. Miller, R. S. Hoerrner, Org. Lett. 2003, 5, 285-287. 
[19] C. E. Paul, I. Lavandera, V. Gotor-Fernández, W. Kroutil, V. Gotor, ChemCatChem 2013, 5, 3875-3881.

[20] M. Karabec, A. Łyskowski, K. C. Tauber, G. Steinkellner, W. Kroutil, G. Grogan, K. Gruber, Chem. Commun. 2010, 46, 6314-6316.

[21] F. R. Bisogno, E. García-Urdiales, H. Valdés, I. Lavandera, W. Kroutil, D. Suárez, V. Gotor, Chem. Eur. J. 2010, 16, 11012-11019.
[22] S. Leuchs, L. Greiner, Chem. Biochem. Eng. Q. 2011, 25, 267-281.

[23] S. Kara, D. Spickermann, A. Weckbecker, C. Leggewie, I. W. C. E. Arends, F. Hollmann, ChemCatChem 2014, 6, 973-976. 


\section{Entry for the Table of Contents}

\section{COMMUNICATION}

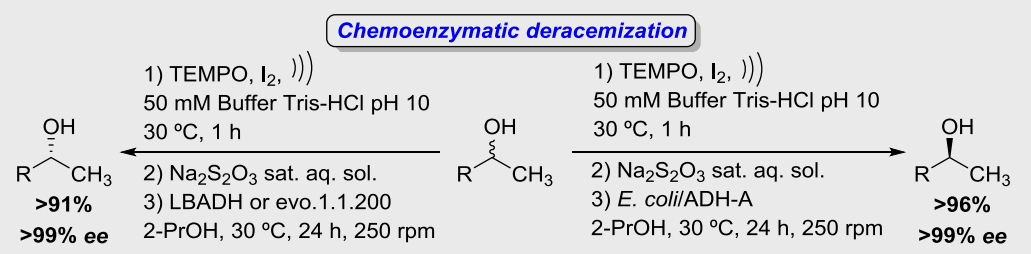

A deracemization of secondary alcohols is described combining in one-pot a chemical oxidation step using TEMPO and iodine, followed by $\mathrm{ADH}$-catalyzed bioreduction. 1-Arylethanols and lineal aliphatic alcohols are obtained with excellent conversions and enantiomeric excess values. The selection of Prelog or anti-Prelog enzymes, allows the isolation of enantiopure alcohol antipodes with excellent overall yields
Daniel Méndez-Sánchez, Juan MangasSánchez, Iván Lavandera, Vicente Gotor and Vicente Gotor-Fernández*

Page No. - Page No.

Chemoenzymatic Deracemization of Secondary Alcohols Using a TEMPOlodine-Alcohol Dehydrogenase System 